\title{
Changes in geochemical foreshore attributes as a consequence of intertidal shellfish aquaculture: a case study
}

\author{
L. I. Bendell*', C. Duckham, T. L'Espérance, J.A. Whiteley \\ Department of Biological Sciences, Simon Fraser University, 8888 University Drive, Burnaby, \\ British Columbia V5A 1S6, Canada
}

\begin{abstract}
On the west coast of British Columbia (BC), Canada, the intertidal is under pressure by commercial farming of the non-native Manila clam Venerupis philippinarum. We applied a 3-tiered approach to determine how farming practices were affecting the geochemical attributes of the intertidal. We compared farmed and reference sites with respect to \% silt, organic matter, ammonium, phosphorus, iron and manganese in surface $(0$ to $3 \mathrm{~cm})$ and bulk $(0$ to $10 \mathrm{~cm})$ sediments. Ammonium porewater profiles and sediment sorption coefficients were determined for 1 of the 3 regions where the greatest intensity of shellfish farming occurred (Tier I). Mesocosm studies were conducted in which intertidal species were manipulated to match the community composition on the farmed as compared to reference sites (Tier II). Microcosm studies were applied to determine how shifts in community structure as observed on farmed versus reference sites and as manipulated in the mesocosm studies, altered the rate of ammonium diffusion to overlying surface waters (Tier III). All geochemical attributes and ammonium sorption coefficients were greater in either surficial and/or bulk sediments of farmed as compared to reference beaches. Tier III studies indicated that the rate of ammonium diffusion from sediments to surface waters was less in microcosms with only bivalves compared to those with mussels, barnacles and bivalves. Tier I and II studies suggest that greater recovery of ammonium and phosphorus is related to increased bivalve density and \% plant coverage on farmed versus reference sites. In contrast, greater amounts of organic matter and silt are due to the presence of antipredator nets. Farming practices that ensure well aerated sediments and support a diverse intertidal community would be advised so that important nutrient geochemical cycles are not altered such to be a detriment to the quality of habitat or to interfere with primary productivity.
\end{abstract}

KEY WORDS: Intertidal · Community composition · Shellfish aquaculture $\cdot$ Nutrients · Organic matter $\cdot$ Nitrogen $\cdot$ Phosphorous $\cdot$ Iron

\section{INTRODUCTION}

The foreshore or intertidal is one of earth's most dynamic and complex ecosystems. Storm events and tides ensure a constantly changing environment. The intertidal is home to thousands of species that make their niches either on the surface of the sediment or within the surficial sediments (Lamb \& Hanby 2005). Epibenthic species such as mussels, which filter algae from the overlying water, provide organic rich materi- als to the sediment water interface through biodeposition. Endobenthic species aerate and mix the sediments through bioturbation while recycling materials supplied by mussels and other surface filter feeders. Endobenthic species also feed on phytoplankton within intertidal interstitial waters and the overlying water column (Solan et al. 2004). The combined functions of these and endobenthic species cycle key nutrients such as organic matter, nitrogen and phosphorus within the intertidal. 
Given the importance of the intertidal as the interface between terrestrial and oceanic processes, much attention has been given to the behaviour of nutrients within this region with possibly nitrogen being the most well studied of the nutrients required for primary productivity (e.g. Enoksson 1993, Twichell et al. 2002, Hou et al. 2003, Burgin \& Hamilton 2007, Fulweiler et al. 2007, Serpa et al. 2007). Perhaps receiving less attention although no less important are iron and phosphorus (reviewed in Newell 2004). A review of the literature suggests that while the geochemical cycling of these elements on the intertidal is complex, amounts of organic matter and hence oxygen availability are key drivers in their geochemical transformations (e.g. Jensen et al. 1995, Gunnars \& Blomqvist 1997, Newell 2004, Fulweiler et al. 2007). In the simplest of descriptions, in the presence of oxygen, all forms of nitrogen are present and nitrification occurs, that is the oxidation of ammonia to nitrate that is then incorporated into biological components. In the absence of oxygen, denitrification occurs with the build-up of ammonium within sediments. Changes to iron and phosphorus that would be expected under anaerobic versus aerobic conditions include the dissolution of iron-phosphate compounds with the release of reduced iron and phosphate (e.g. Jensen et al. 1995, Rozan et al. 2002, Testa et al. 2002). Hence, anthropogenic activities that affect the amounts of organic matter to the intertidal, and thereby the occurrences of aerobic or anaerobic conditions, will also determine the cycling of nutrients sensitive to these abiotic conditions.

Anthropogenic activities that lead to increased amounts of organic matter on the foreshore include urbanization, logging, and terrestrial and aquaticbased agriculture (e.g. Simenstad et al. 1993, Jickells \& Rae 1997, Spencer et al. 1997, Bendell-Young 2006). All these activities are increasing due to an ever increasing human population. Further, as the need for a secure source of protein escalates, there is an ever increasing pressure to develop alternate protein sources such as shellfish aquaculture. As a consequence, much study has been given to the influences of cultivated populations of suspension feeding bivalves on ecosystem processes (Smaal et al. 2001, reviewed by Newell 2004, Giles 2006, D'Amours et al. 2008). In the case of suspension feeding bivalves, study is directed on the role of increased biodeposition from the bivalves. Primary changes in sediment geochemistry and nutrient fluxes are related to amounts of organic matter supplied by the biodeposits which change the underlying sediments from aerobic to anaerobic conditions.

The constantly changing environment of the intertidal presents an added challenge towards fully under- standing how geochemical cycles are influenced by activities such as near bottom mariculture. Hence, the influences of cultivated bivalve populations on the ecosystem may not be directly applicable to processes occurring in intertidal zones. The intensive farming of the intertidal Manila clam Venerupis philippinarum, is in the focus of the current study.

Shellfish farming practices as applied in British Columbia (BC), Canada, involve a number of invasive activities including clearing the beach of competing species, such as the native littleneck clam Protothaca stamenia, as well as removal of epibenthic species such as mussels Mytilus trossulus and barnacles Balanus glandula. The cleared area is seeded with immature Manila clams and the region then covered in antipredator netting (Jamieson et al. 2001). The netting can be made from plasticfoil with $1.25 \mathrm{~cm}$ apertures or woven rope with apertures up to $3.5 \mathrm{~cm}$. Nets are thought to prevent predation of the clams by clam eating ducks (e.g. the surf scoter Melanitta perspicillata) although recent work has demonstrated that there is no evidence that the nets actually achieve this function (Whiteley \& Bendell-Young 2007). Further details with respect to farming procedures can be found in Jones et al. (1993).

Two effects could influence the cycling of nutrients within the intertidal: (1) The presence of the nets creating a physical barrier between the overlying water column and sediment restricting water flow. This in turn could lead to the entrainment of silts and accumulations of organic matter, which would favour anaerobic conditions. In addition to the net itself acting as a barrier, the nets become biofouled with algae (Jamieson et al. 2001). This would further restrict the movement of oxygen and other nutrients from the overlying water column into the sediment (e.g. Corzo et al. 2009). (2) The shift from an intertidal community with both benthic endobenthic species to one with predominantly endobenthic species (e.g. Spencer et al. 1997, Bendell-Young 2006). The consequence would be the disruption of benthic-pelagic coupling and of the supply of nutrients from the overlying water column to the sediments.

Our objectives were therefore two-fold: (1) to determine whether anti-predator nets in combination with biofouling lead to accumulation of silt and organic matter and to anaerobic conditions resulting in loss of redox sensitive elements such as iron and manganese and accumulation of ammonium; (2) to determine whether removal of epibenthic organisms alters the flux of nutrients such as nitrogen and phosphorus to the overlying water column. Our working hypothesis is that the combined effects will result in lower recovery of iron, manganese and phosphorus with corresponding accumulations of ammonium, or- 
ganic matter and silt in sediments of farmed as compared to reference sites.

Shellfish aquaculture occurs in sheltered bays and estuaries because they offer suitable substrate (see DFO 2006). On the west coast of BC, such areas are highly productive environments and key habitats for many migratory species. However, these sensitive estuarine habitats account for only $2.3 \%$ of the BC coastline (MoE 2006). Understanding the impacts of an industrial activity such as shellfish farming on these sites is essential for proper management of these critical habitats. This study also provided an opportunity to assess in general how large scale manipulations in intertidal community structure influence the geochemical cycling of nutrients on the intertidal. In this case, by shifting a naturally diverse community of epi- and endobenthic species to one dominated by bivalves, largely comprised of the intentionally introduced non-native Manila clam. In addition, the invasive varnish clam Nuttallia obscurata is presently establishing in certain regions of the west Canadian foreshore. Introduced 15 years ago via ballast waters, it is rapidly becoming the dominate bivalve on the intertidal. This species reaches densities of 800 individuals $\mathrm{m}^{-2}$ (Dudas 2005, Dudas \& Dower 2006), two to threefold greater than those of the farmed Manila clam or the indigenous populations (Whiteley \& Bendell-Young 2007). Hence, outcomes of our study may provide some insight as to how such shifts in community structure, either intentional through aquaculture or non-intentional through introduction of invasive species, change the movement of nutrients within the foreshore.

\section{MATERIALS AND METHODS}

We adopted a 3-tiered approach: field sampling (Tier I), in situ mesocosm studies (Tier II), and laboratory microcosm studies (Tier III) (Table 1). For Tier I, 2 compounded aspects were addressed: the physical presence of anti-predator netting coupled with a shift in community structure. In the absence of predator net- ting, Tier II and Tier III studies were designed to, explore the effect that shifting the intertidal community from one comprised of both epi- and endobenthic species to one with just endobenthic bivalves, will have on nutrient geochemical cycles. In this way, we hoped to tease out the possible contributions of each to cumulative effects measured in the field.

Field sampling (Tier I). Three sheltered intertidal ecosystems on the North West coast of Canada were sampled for sediment geochemistry (Fig. 1). We applied a paired sampling regime: a reference beach and a farmed beach. Physical characteristics such as habitat, slope, sediment composition (e.g. cobbles vs mud) were matched as closely as possible between the paired sites to minimise natural intertidal heterogeneity (Table 2; see Whiteley \& Bendell-Young 2007 for further study site details). Farmed sites were small local industries accessed with permission from the shellfish farmers. Farmed beaches had been active from 1 to 10 yr (Table 2).

Sediments: Paired sites were sampled at Desolation Sound (2 sites), Baynes Sound; and Barkley Sound; (8 reference and 8 farmed for a total of 16 intertidal sites) for bulk (upper 0 to $10 \mathrm{~cm}$ ) sediment in the first summer field season. With the exception of site D1 in Desolation Sound, intertidal sites were again sampled for surficial (upper 0 to $3 \mathrm{~cm}$ ) sediment the following summer field season $(7$ reference and 7 farmed for a total of 14 intertidal sites). At each beach, between the low and mid-tide (mid-tide was defined as 1 to $2.7 \mathrm{~m}$ above chart datum and low tide between chart datum and $1 \mathrm{~m}), 12$ to 18 points were randomly chosen. A stainless steel box corer $(0.5 \times 0.5 \times 0.3 \mathrm{~m})$ was placed at these points, and from 1 corner samples were collected with a $4.5 \mathrm{~cm}$ polyurethane core tube. To collect the upper 0 to $3 \mathrm{~cm}$ of sediment, the tube was inserted only into this range of sediment. To collect the 0 to $10 \mathrm{~cm}$ of sediment, the tube was inserted to a depth of $10 \mathrm{~cm}$. Samples were placed in labelled whirlpack bags, homogenized within the bag, placed on ice, transported to the lab and frozen at $-20^{\circ} \mathrm{C}$ until nutrient and silt analyses.

Bivalves and plant cover: At each beach, 12 to 18 samples were randomly taken between low and mid

Table 1. Summary of the 3-tiered approach

\begin{tabular}{|c|c|c|c|c|}
\hline Tier & Study level & Study subject & Procedure & Measured attribute(s) \\
\hline I & Field & $\begin{array}{l}\text { Anti-predator netting and } \\
\text { shift in community } \\
\text { structure }\end{array}$ & $\begin{array}{c}\text { Field } \\
\text { sampling }\end{array}$ & $\begin{array}{l}\text { Geochemistry in bulk and surficial } \\
\text { sediment, porewater profiles for ammonium } \\
\text { and ammonium sorption coefficients }\end{array}$ \\
\hline II & Mesocosm & $\begin{array}{l}\text { Shift in community } \\
\text { structure }\end{array}$ & $\begin{array}{l}\text { Community } \\
\text { manipulations }\end{array}$ & $\begin{array}{l}\text { Sediment geochemistry in surface } \\
\text { sediments at } t=0,1,2,4 \text { and } 16 \mathrm{~d}\end{array}$ \\
\hline III & Microcosm & $\begin{array}{l}\text { Shift in community } \\
\text { structure }\end{array}$ & $\begin{array}{l}\text { Community } \\
\text { manipulations }\end{array}$ & $\begin{array}{c}\text { Rates of ammonium } \\
\text { diffusion }\end{array}$ \\
\hline
\end{tabular}



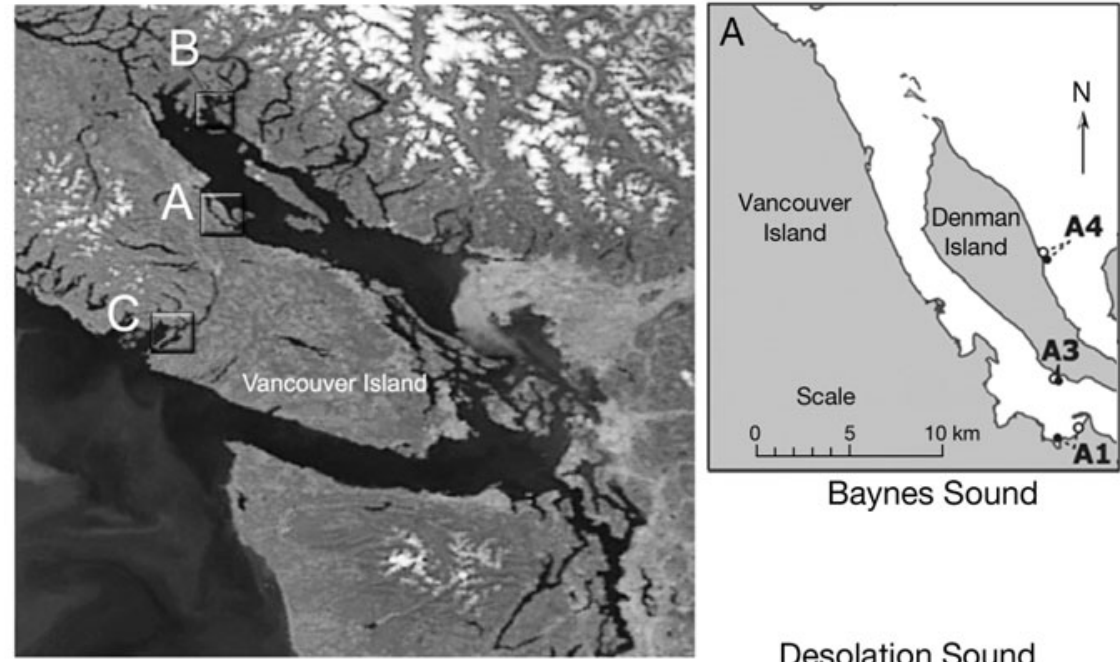

Baynes Sound

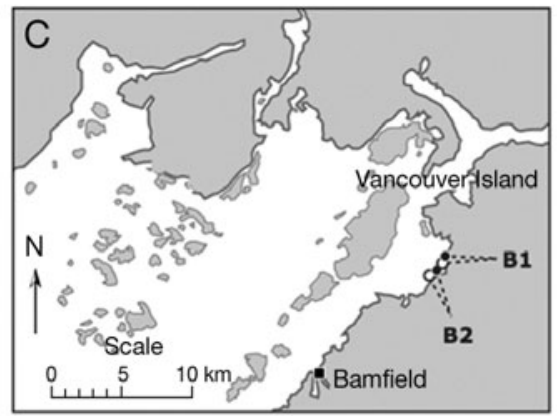

Barkley Sound

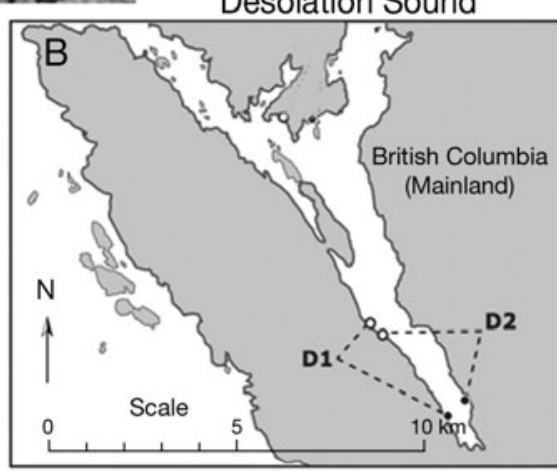

Fig. 1. Study sites: (O) reference site, (•) farm site. Two sites were sampled at location A1: A1a and A1b tide. The box corer was inserted into the substrate and all sediment to a depth of $20 \mathrm{~cm}$ was removed by shovel and sifted through a $6 \mathrm{~mm}$ mesh sieve to remove large organisms. A subsample of sediment $(0.25 \times 0.25 \mathrm{~m})$ from 1 corner of each quadrat was passed through a $1 \mathrm{~mm}$ mesh sieve under the $6 \mathrm{~mm}$ sieve to capture smaller individuals. Sediment retained in each sieve was hand-sifted to locate organisms. Infaunal bivalves were identified in the field to the lowest taxonomic level possible, usually species, using field guides (Whiteley \& Bendell-Young 2007). All bivalves were returned to the sediment post-sampling. Within each $0.5 \times 0.5 \mathrm{~m}$ quadrat, plant cover was estimated for algae, mosses, and other modular or colonial organisms on the surface of nets and sediment. Cover was recorded as a percentage of the total quadrat area occupied by the species. It is possible for total cover to exceed $100 \%$, in the event of species being layered atop one another. A single species, however, may not exceed $100 \%$ cover.

Pore waters: Of the 3 regions,

Table 2. General characteristics of the study sites. F: farmed, $\mathrm{R}$ : reference

\begin{tabular}{|c|c|c|c|c|c|}
\hline Region & Site & Type & $\begin{array}{l}\text { Size } \\
\left(\mathrm{m}^{2}\right)\end{array}$ & $\begin{array}{l}\text { Netted } \\
(\mathrm{yr})\end{array}$ & $\begin{array}{c}\text { Sediment } \\
\text { type (visual) }\end{array}$ \\
\hline \multicolumn{6}{|c|}{ Baynes Sound } \\
\hline & \multirow[t]{2}{*}{$\mathrm{A} 1 \mathrm{a}$} & F & 500 & \multirow[t]{2}{*}{4} & Silt/Sand \\
\hline & & $\mathrm{R}$ & 11638 & & Sand/Silt \\
\hline & \multirow[t]{2}{*}{$\mathrm{A} 1 \mathrm{~b}$} & $\mathrm{~F}$ & 3650 & \multirow[t]{2}{*}{4} & Gravel/Sand \\
\hline & & $\mathrm{R}$ & 8575 & & Sand/Silt \\
\hline & \multirow[t]{2}{*}{ A3 } & $\mathrm{F}$ & 1120 & \multirow[t]{2}{*}{6} & Gravel/Sand \\
\hline & & $\mathrm{R}$ & 995 & & Gravel/Sand \\
\hline & \multirow[t]{2}{*}{ A4 } & F & 7965 & \multirow[t]{2}{*}{4} & Cobble/Gravel \\
\hline & & $\mathrm{R}$ & 21750 & & Cobble/Gravel \\
\hline \multicolumn{6}{|c|}{ Barkley Sound } \\
\hline & \multirow[t]{2}{*}{ B1 } & $\mathrm{F}$ & 1158 & \multirow[t]{2}{*}{1} & Gravel/Sand \\
\hline & & $\mathrm{R}$ & 800 & & Gravel/Silt \\
\hline & \multirow[t]{2}{*}{ B2 } & F & 1190 & \multirow[t]{2}{*}{1} & Gravel/Sand \\
\hline & & $\mathrm{R}$ & 501 & & Gravel/Sand \\
\hline \multicolumn{6}{|c|}{ Desolation Sound } \\
\hline & \multirow[t]{2}{*}{ D1 } & F & 739 & \multirow[t]{2}{*}{10} & Gravel/Sand \\
\hline & & $\mathrm{R}$ & 700 & & Gravel/Sand \\
\hline & \multirow[t]{2}{*}{ D2 } & $\mathrm{F}$ & 449 & \multirow[t]{2}{*}{7} & Gravel/Sand \\
\hline & & $\mathrm{R}$ & 342 & & Gravel/Sand \\
\hline
\end{tabular}

Baynes Sound is most intensively used for shellfish aquaculture (Jamieson et al. 2001). For this reason, iron and ammonium in pore waters and ammonium sediment sorption coefficients for the surficial sediment were determined for farmed and reference sites within this region. Nutrient pore water profiles were determined using pore water peepers after Thomas \& Bendell-Young (1999). Replicate peepers were placed in 2 or 3 locations within 3 farmed and 3 reference sites. Peepers were equilibrated for $14 \mathrm{~d}$, and sampled for ammonium at time of peeper retrieval with an Oakton ${ }^{\circledR}$ Acorn $^{\mathrm{TM}}$ Series Ion 6 ammonium electrode. Time from peeper removal to complete sampling of the peeper chambers was $<10 \mathrm{~min}$. The average ammonium concentration for interstitial waters for the upper $3 \mathrm{~cm}$ of sediment was calculated, and the ammonium sediment sorption coefficient. Kd was determined for each site as: $\mathrm{mg} \mathrm{g}^{-1}$ ammonium in sediment $\times\left(\mathrm{mg} \mathrm{l}^{-1} \text { ammonium in porewaters }\right)^{-1}$.

In situ mesocosm studies (Tier II). Tier II and III studies were designed to, in the absence of predator netting, explore the effect of shifting the intertidal community from one comprised of both epi- and endo- 
benthic species to one with just endobenthic species, i.e. the effect bivalves will have on nutrient geochemical cycles.

Mesocosms were located in Fillongley Park, Denman Island (site A4, Fig. 1). Twelve cages (PVC pipe frame, $1 \times 1 \times 0.3 \mathrm{~m}$, enclosing $1 \mathrm{~m}^{2}$ ) were dug into the sediment to a depth of $0.2 \mathrm{~m}$, leaving $0.1 \mathrm{~m}$ exposed. All sides of the frames including the surface were covered with a plastic mesh $(1 \times 1 \mathrm{~cm}$ aperture $)$. Mesh covers were fixed at $10 \mathrm{~cm}$ above the sediment-water interface to allow the free flow of seawater. A $4 \times 3$ grid was created with each mesocosm spaced $\sim 2 \mathrm{~m}$ apart and located between 1.4 and $1.7 \mathrm{~m}$ above chart datum. One yr prior to community manipulations, sediments from within cages were sieved through a $6 \mathrm{~mm}$ mesh to remove macrofauna and returned to cages. Whiteley (2005) found that only $10 \%$ of species and $25 \%$ of species count data were lost using $6 \mathrm{~mm}$ versus $1 \mathrm{~mm}$ sieve mesh. Mesocosms were allowed to settle for $1 \mathrm{yr}$. Then they were randomly grouped into 4 groups of 3 and communities were manipulated as (1) reference (no Manila clams, mussels or barnacles); (2) just mussels Mytilus trossulus and barnacles Balanus glandula (204 \pm 79 [SE] and $1962 \pm 732$ respectively); (3) just Manila clams (200 \pm 0$)$; and (4) mussels, barnacles and Manila clams $(366.6 \pm 68,1626 \pm 438$ and $200 \pm 0]$ respectively). Invertebrates were collected from the adjacent beach: Manila clams (35 mm length), mussels (30 to $50 \mathrm{~mm}$ length) and barnacles (3 to $5 \mathrm{~mm}$ diameter) and were stocked in densities that represented average numbers $\mathrm{m}^{-2}$ found on reference sites (Whiteley \& Bendell-Young 2007). Surficial sediments were sampled at time 0 (prior to manipulations), and after 1 , 2, 4 and $16 \mathrm{~d}$. Sampling over the $16 \mathrm{~d}$ periods was done to include 2 complete wk of tidal cycles. Each mesocosm was sampled in triplicate, $(9$ samples per treatment) $\times(4$ treatments $) 36$ samples for each day. It is important to note that the use of a $1 \mathrm{~cm}^{2}$ mesh will allow all intertidal species $\leq 1 \mathrm{~cm}$ in size into the mesocosms. Assessing community composition prior to community manipulation would have disturbed our initial conditions. Hence the purpose of the mesocosms with no clams, barnacles or mussels is to serve as a geochemical reference for those mesocosms with added invertebrates.

Laboratory microcosm studies (Tier III). Rates of ammonium diffusion. In the wet laboratory at Simon Fraser University, 12 microcosms were established. Temperature was constant at $10^{\circ} \mathrm{C}$. Microcosms were plastic containers of $0.25 \times 0.5 \mathrm{~m}$. To each was added a slurry of $1.5 \mathrm{l}$ of sediment and $1 \mathrm{l}$ of seawater (28 ppt). The sediment was allowed to settle and a slurry of $75 \mathrm{ml}$ pureed organic matter (aquatic plants) and 41 of seawater was added. Microcosms were continually aerated with airstones throughout the duration of the experiment. This also served to keep the overlying water well mixed. Sediments were from Fillongley Park, Baynes Sound (site A4, Fig. 1) and had been sieved through a $1 \mathrm{~mm}$ mesh to remove all macrofauna. Microcosms were allowed to settle for $5 \mathrm{~d}$ at which time initial conditions (time $=0$ ) were taken. Four groups of 3 contains each were randomly assigned and communities were manipulated as (1) reference, no invertebrates added; (2) 20 Manila clams; (3) 20 mussels and ca. 60 to 80 barnacles; and (4) 10 Manila clams, 10 mussels and 60 to 80 barnacles. As with sediments, invertebrates were collected from Fillongley Park, transported in a cooler and placed into the microcosms within $24 \mathrm{~h}$ of collection. Clams were of harvestable size, $35 \mathrm{~mm}$ in length, mussels ca. 30 to $40 \mathrm{~mm}$ in length, and barnacles ca. 3 to $5 \mathrm{~mm}$ in base diameter. Density of clams, mussels and barnacles were $160 \mathrm{~m}^{-2}, 160 \mathrm{~m}^{-2}$ and 560 $\mathrm{m}^{-2}$, respectively for microcosms with clams and mussels alone. To allow comparison of rates of ammonium diffusion among communities for the community where clam and mussels were combined, the combined density was equalled to the density of clams or mussels alone.

At Days 0, 1, 2, 3, 4, 5, 6, 7, 8, 10, 12, 14 and 16, 1 sample of pore water and overlying surface water was taken from each microcosm (3 replicates per treatment $\times 4$ treatments $=12$ samples) for ammonium analysis. Pore water ( 3 to $5 \mathrm{ml}$ ) was obtained by sampling $5 \mathrm{ml}$ of sediment, centrifuging the sediment for $5 \mathrm{~min}$ at $3000 \mathrm{rpm}$, and then giving the supernatant through a $0.45 \mu \mathrm{m}$ millipore filter. Surface water was collected through a $0.45 \mu \mathrm{m}$ millipore filter, via syringe. All microcosms were topped-up with fresh seawater to keep volumes constant throughout the $16 \mathrm{~d}$ sampling period. Samples were frozen prior to ammonium analysis. Freezing has been shown to be an effective way of stabilizing ammonium concentrations in samples that cannot be analyzed immediately (Nollet 2000). At time of analysis, samples were thawed and ammonium determined with an Oakton ${ }^{\circledR}$ Acorn $^{\mathrm{TM}}$ Series Ion 6 electrode calibrated with standards. At Days 0 and 16, $5 \mathrm{ml}$ of sediment was taken from each microcosm via syringe, for organic matter determination.

Geochemical attributes of sediments. Organic matter, ammonium and phosphate: Organic matter was determined as loss on ignition (samples ignited at $400^{\circ} \mathrm{C}$ for $1 \mathrm{~h}$ ). Sediment ammonium was determined using the indophenol blue method (Page et al. 1982). Sediment (10 g) was mixed with $2 \mathrm{M}$ potassium chloride. After the sediment had settled, $1 \mathrm{ml}$ EDTA, $2 \mathrm{ml}$ phenol-nitroprusside solution and $4 \mathrm{ml}$ of buffering solution were combined with $5 \mathrm{ml}$ of the sediment extract, diluted to volume, then heated 
for $30 \mathrm{~min}$ at $40^{\circ} \mathrm{C}$. Samples were cooled, and absorbance was determined by spectrophotometer at $636 \mathrm{~nm}$. Concentrations of ammonium were determined from calibration curves derived from laboratory standards. Sediment phosphate was determined after Greenberg et al. (1992). Sediment (5 g) was placed in a Teflon tube and $0.1 \mathrm{~N}$ sulphuric acid (1 $\mathrm{ml})$ and concentrated nitric acid $(5 \mathrm{ml})$ were added. The samples were placed in a CEM MDS2000 Microwave for $18 \mathrm{~min}$ at $200^{\circ} \mathrm{C}$. Each sample was filtered and diluted to $100 \mathrm{ml}$ using distilled water. In $50 \mathrm{ml}$ Falcon tubes, $2.5 \mathrm{ml}$ distilled water, $5 \mathrm{ml}$ vanadate-molybdate reagent and $17.5 \mathrm{ml}$ of the sample was mixed, and absorbance read by a spectrophotometer at $470 \mathrm{~nm}$. Sediment phosphate concentrations were derived from calibration curves generated by standards solutions. Accuracy was checked through inclusion of laboratory made standards. Procedural blanks were always below detection and ensured confidence in our methods.

Iron, manganese and \% silt: Iron and manganese were extracted from a $5 \mathrm{~g}$ sample of sediment using aqua regia. A subsample of extract was diluted to $10 \mathrm{ml}$ with distilled deionised water and iron and manganese concentrations determined with a Perkin Elmer model 100 atomic absorption spectrophotometer. Precision of analysis as determined by the coefficient of variation of 10 repeated measures of iron and manganese extracted from marine sediment standard reference material (NIST SRM) was 10 and $5.5 \%$ for iron and manganese respectively. Procedural blanks indicated no background interferences or contamination. To determine \% silt, $100 \mathrm{~g}$ of sediment was dried for $48 \mathrm{~h}$. Dried sediment was separated into 4 grain size fractions through wet sieving: gravel $(>2 \mathrm{~mm})$, coarse sand (>0.5 mm), fine sand ( $>0.0625 \mathrm{~mm})$. Each size fraction was dried for $24 \mathrm{~h}$ and weighed. The silt fraction was calculated from the total dry weight less the weight of the 3 sieved fractions.

Statistical analysis. All analyses were conducted using Statistical Analysis System made available through Simon Fraser University (2002-2003) by SAS Institute, Cary, North Carolina, USA. Data normality was assessed through normality plots, and although there were some deviations from normality (slightly positively skewed), these were not severe enough to warrant transformation of the data. Obvious outliers $(3 \times \mathrm{SD})$ were excluded from further statistical analysis (Osborne \& Overbay 2004). To avoid problems with bimodality, \% plant cover was transformed to arcsine (square root \%) prior to statistical analysis. For paired $t$-tests, equality of variances of the variables was also tested and although not required for a paired test, variances were the same between farmed and reference sites.
Tier I: Paired $t$-tests were used to determine differences in average nutrient concentrations, bivalve density and \% plant cover for the paired farmed and reference sites. Bivariate plots were applied to determine correlations between intertidal biotic and abiotic variables. Pore water profiles for each site were averaged ( $\mathrm{n}=4$ to 6 ), and profiles (average $\pm \mathrm{SE}$ ) for ammonium and iron plotted against depth, in cm intervals, for each paired site (farm and reference). Differences in Kd for farmed and reference sites in ammonium adsorption coefficients were determined through Student's $t$-tests.

Tier II: Paired $t$-tests (i.e. before and after) were used to evaluate if nutrient concentrations (calculated as nutrient concentration at $\mathrm{t}=1,2,4$ and $16 \mathrm{~d}$ minus nutrient concentrations determined at $\mathrm{t}=0$ ) were different from 0 for each of the 4 community manipulations.

Tier III: To determine rates of ammonium diffusion (concentration of ammonium diffusing either to or from sediments $\mathrm{d}^{-1}$ ) for each time, the concentration of ammonium determined in pore waters was subtracted from the corresponding concentration of ammonium in the overlying surface water. The difference ([ammoni$\left.u_{\text {porewater }}\right]-\left[\right.$ ammonium $\left._{\text {surfacewater }}\right]$ ) was regressed with time of sampling and slopes (where the slopes are rates of ammonium diffusion) of the regressions determined for each of the 4 communities. For time series data such as that obtained from the Tier III experiments, the ordinary regression residuals usually are correlated over time. Therefore, use of ordinary regression analysis for time series data may be inappropriate since the assumptions on which the classical linear regression model is based may be violated. We applied an AUTOREG linear regression (SAS 9.1.3) to solve this problem by augmenting the regression model with an autoregressive model for the random error, thereby accounting for the autocorrelation of the errors. Difference in sediment organic matter at $t=0$ and $t=16$ for each of the 4 treatments was determined by Student's $t$-test.

\section{RESULTS}

\section{Field studies (Tier I)}

Overall trends in sediment geochemistry. Paired $t$-tests indicated that farmed sites contained significantly greater amounts of ammonium, phosphorus and manganese in bulk and organic matter, and ammonium, iron, manganese and silt in surficial sediments. Organic matter, iron and silt did not differ between farmed or reference bulk sediments (Table 3).

Site specific trends in sediment geochemistry. Bivariate plots for each of the paired reference and 
farmed sites for both bulk and surficial sediments demonstrate variability within site and the general relationship in geochemical composition of bulk as compared to surface sediments (Fig. 2a-f). Generally, geochemical characteristics of bulk sediments are similar to those of surficial sediments, with nutrients generally greater in farmed as compared to the paired reference site (see Table 3).

Biotic variables. The Manila clam was the dominating bivalve within the intertidal. The order of bivalve dominance was as Venerupis philippinarum, Macoma balthica, Cryptomya californica, Protothaca staminea, and $M$. nasuta for farmed sites and $V$. philippinarum, M. balthica, C. californica, M. nasuta, and N. obscurata for reference sites. The dominant macroalgae that comprised the majority of estimated coverage (i.e. $>20 \%$ ) was Ulva spp. $<20 \%$ coverage included the algae Endocladia muricata, Gracilario spp., and Fucus gardneri (on 1 farmed beach only) and the eelgrass Zostera marina (on 1 reference site only). Bivariate plots of clam density versus plant coverage indicated weak positive correlations between the 2 variables $(p>$ $0.1<0.15)$. Generally clam density and \% plant coverage were greater on farmed as compared to reference sites (Table 3, Fig. 3a,b).

Relationships with biotic variables. Bivariate plots of the geochemical attributes in bulk and surficial sediments indicated that only nutrient concentrations in surficial sediments were correlated positively with bivalve density, with significant relationships for ammonium $(r=0.5)$, iron $(r=0.57)$ and silt $(r=0.6)$ (Figs. $4 \mathrm{a}-\mathrm{h} ; \mathrm{p}<0.05$, manganese and silt not shown). In contrast, the only nutrient in bulk sediments that was correlated with increasing plant coverage was ammonium (Fig. 5, r = 0.57; p < 0.05).

Iron and phosphorus in bulk and surficial sediments. Bivariate plots of phosphorus and iron in bulk and surface sediments showed that, for reference sites, the 2 variables were positively correlated $(\mathrm{r}=0.77$ and 0.76 respectively; $\mathrm{p}<0.05)$. No correlations were noted for farmed sites (Figs. 6).

Pore water profiles for ammonium and ammonium sorption coefficients. Pore water profiles for ammonium from 3 farmed and their paired reference sites located in Baynes Sound are given in Fig. 7. Generally, profiles indicated increases in ammonium with depth for both beach types. Ammonium sorption coefficients pooled by intertidal type were: $\mathrm{Kd}=0.01 \pm 0.00063$ $(\mathrm{SE})$ and $0.008 \pm 0.00068$ and were significantly greater for farmed versus reference sites respectively (Student's $t$-test; $\mathrm{p}<0.05)$.
Table 3. Overall geochemical and biological attributes in bulk and surficial sediments of farmed as compared to reference beaches. Mean values $\pm \mathrm{SE}$; units: $\mathrm{mg}$ $\mathrm{g}^{-1}$ dry wt for all except for manganese $\left(\mu_{\mathrm{g} \mathrm{g}}{ }^{-1}\right)$ and silt (\%). Bivalve density: $\mathrm{m}^{-2}$. Percent plant cover: values arcsine transformed. ${ }^{*}$ Deep Bay surficial sediments excluded as values were threefold those of the other 6 beaches

\begin{tabular}{|lcccc}
\hline Attribute & Farmed & Equivalency & Reference & $\mathrm{p}$ \\
\hline Bulk sediments $(\mathbf{n}=\mathbf{8})$ & & & & \\
Geochemical & & & & \\
Organic matter & $0.153 \pm 0.007$ & $=$ & $0.13 \pm 0.007$ & 0.23 \\
Ammonium & $0.016 \pm 0.0013$ & $>$ & $0.012 \pm 0.0009$ & 0.01 \\
Phosphorus & $0.132 \pm 0.006$ & $>$ & $0.098 \pm 0.0025$ & 0.0001 \\
Iron & $5.7 \pm 0.35$ & $=$ & $5.92 \pm 0.37$ & 0.7 \\
Manganese & $50 \pm 3.8$ & $>$ & $33.3 \pm 1.8$ & 0.0001 \\
Silt & $0.033 \pm 0.005$ & $=$ & $0.033 \pm 0.004$ & 0.8 \\
Biological & & & & \\
Bivalve density & $402 \pm 45$ & $>$ & $262 \pm 56$ & 0.07 \\
\% plant cover & $0.32 \pm 0.06$ & $=$ & $0.27 \pm 0.05$ & 0.53 \\
Surficial sediments (n & $\mathbf{7})$ & & & \\
Geochemical & & & & \\
Organic matter & $0.18 \pm 0.01$ & $>$ & $0.147 \pm 0.006$ & 0.009 \\
Ammonium* & $0.0217 \pm 0.001$ & $>$ & $0.018 \pm 0.0008$ & 0.006 \\
Phosphorus & $0.09 \pm 0.007$ & $=$ & $0.08 \pm 0.006$ & 0.65 \\
Iron & $3.9 \pm 0.18$ & $>$ & $3.15 \pm 0.13$ & 0.007 \\
Manganese & $47.4 \pm 3.4$ & $>$ & $39.5 \pm 1.95$ & 0.04 \\
Silt & $0.036 \pm 0.004$ & $>$ & $0.025 \pm 0.002$ & 0.0001 \\
Biological & & & & \\
Bivalve density & $481 \pm 64$ & $>$ & $269 \pm 34$ & 0.001 \\
\% plant cover & $0.377 \pm 0.07$ & $>$ & $0.18 \pm 0.03$ & 0.02 \\
\hline
\end{tabular}

\section{Mesocosm studies (Tier II)}

Paired $t$-tests determined whether calculated nutrient differences at Day 1, 2, 4 and 16 were significantly different from Day 0 . A negative value indicates a net decrease, a positive value a net increase in nutrient concentration at each sampling time. Those mesocosms with just Manila clams tended to be lower in organic matter, ammonium and iron as compared to the 3 other communities. In contrast, phosphorus tended to accumulate in surface sediments of clam only and clam, mussel and barnacle communities as compared to the reference and mussel and barnacle communities only. Notable was the greater recovery of ammonium from all mesocosms on Day 16 (although trends remained consistent among the mesocosms, i.e. lower recovery in the clam only mesocosms as occurred for organic matter and iron). No clear patterns in \% silt were apparent, other than for all mesocosms, differences in $\%$ silt at Day 1 tended to be greater than at 

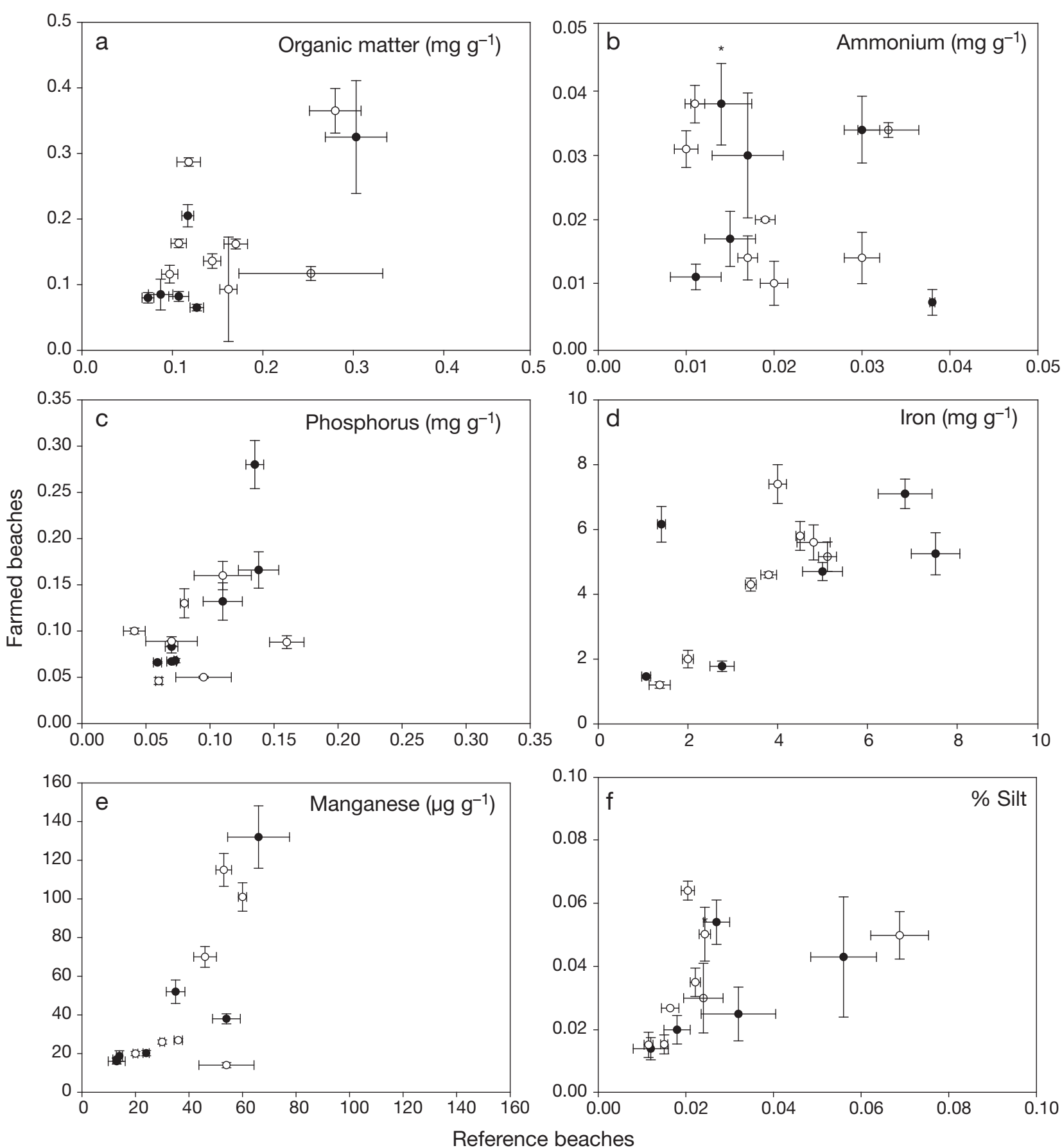

Fig. 2. Nutrients in bulk ( 0 to $10 \mathrm{~cm}$ ) vs. surficial $(0$ to $3 \mathrm{~cm}$ ) sediments from paired reference and farmed beaches. Means of 12 to 18 samples $\pm 1 \mathrm{SE}$, units see panels. (०) surficial sediments, $(\bullet)$ bulk sediments

Day 0 (although not significant) as compared to all other sample times (Figs. 8a-d).

\section{Microcosm studies (Tier III)}

Comparison of the ammonium diffusion rates $\left(\mathrm{mg} \mathrm{l}^{-1}\right.$ $\mathrm{d}^{-1}$ ) showed that microcosms with only clams or mus- sels and barnacles had the same rates of diffusion (0.02 $\mathrm{mg} \mathrm{l}^{-1} \mathrm{~d}^{-1}$ ) (Student's $t$-test; $\left.\mathrm{p}>0.05\right)$. In contrast, microcosms with all 3 invertebrate species present had significantly greater rates of $0.03 \mathrm{mg} \mathrm{l}^{-1} \mathrm{~d}^{-1}, 1.5$ times that of Manila clams, or mussels and clams alone (Student's $t$-test; $\mathrm{p}<0.05$; Figs. 9a-c). Sediment organic matter in $\mathrm{mg} \mathrm{g}^{-1} \pm \mathrm{SE}(\mathrm{n}=3)$ at Day 0 was $0.16 \pm 0.02$, $0.17 \pm 0.03,0.13 \pm 0.02$, and $0.15 \pm 0.03$ for the control, 


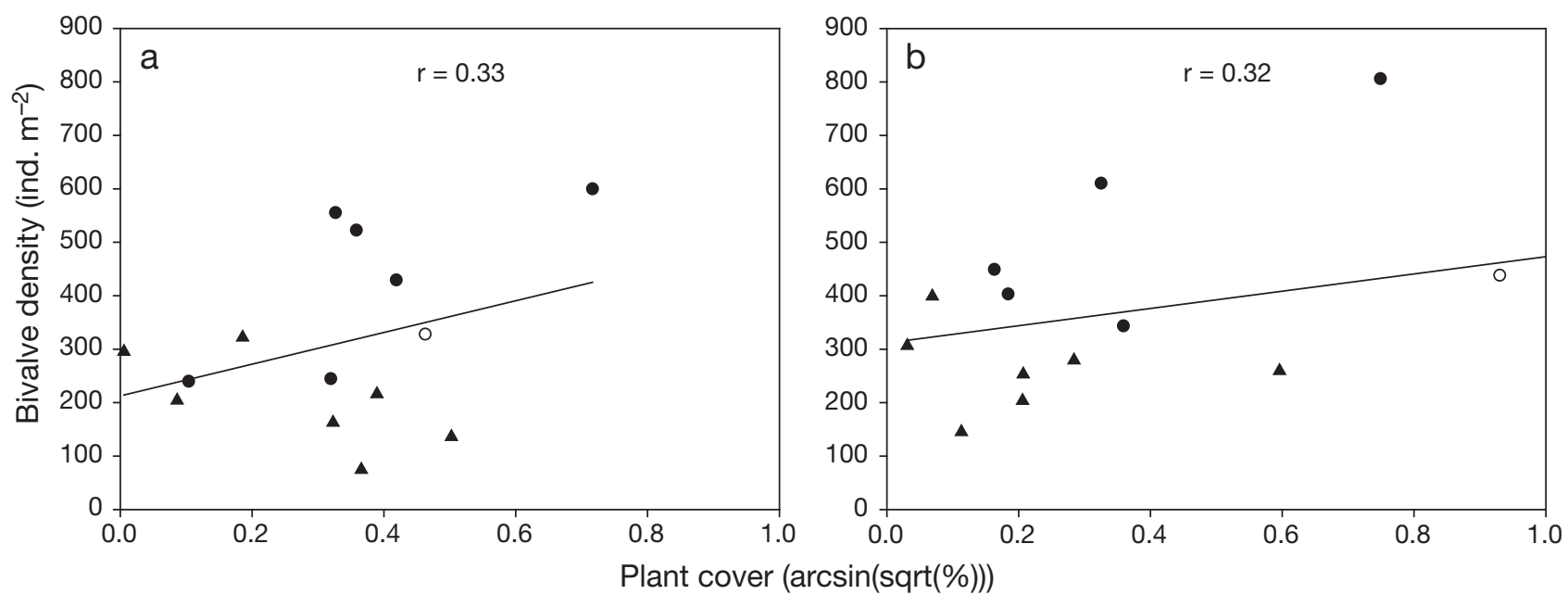

Fig. 3. Bivariate plot of bivalve density and \% plant cover for farmed ( $\bullet$ ) and reference (A) beaches for (a) bulk and (b) surficial sediments

clam only, mussel and barnacle only, and the clam, mussel and barnacle microcosms respectively. At Day 16, sediment organic matter was $0.17 \pm 0.03$, $0.14 \pm 0.01,0.1 \pm 0.027$ and $0.09 \pm 0.014$ for the control, clam only, mussel and barnacle only, and the clam, mussel and barnacle microcosms respectively. With the exception of the control microcosm, all values for organic matter were significantly less at Day 16 as compared to Day 0 ( $\mathrm{p}<0.05$, Student's $t$-test) suggesting that invertebrates were actively feeding throughout the experiment.

\section{DISCUSSION}

Previous studies (Sorokin et al. 1999, Bartoli et al. 2001, Beadman et al. 2004, Bendell-Young 2006) have shown that netted farmed sites tend to have more of organic matter and silt as compared to reference sites. Intensive shellfish farming also leads to loss of benthic diversity and changes in species composition towards netted regions being dominated by bivalves and deposit feeding worms as compared to paired reference beaches (Spencer et al. 1997, Bendell-Young 2006). Powers et al. (2007) have reported that macroalgae growing on bivalve netting enhance nursery habitat for mobile invertebrates and juvenile fishes as compared to an unstructured sandflat. The macrophyte in this case, however, was eelgrass Zostera marina, which does not form an anaerobic barrier as does the alga Ulva, which occurs on beaches in the Pacific Northwest. Our hypothesis was that given the physical presence of netting and its associated biofouling, the corresponding higher amounts of organic matter, and the changing community composition, the geochemical cycles of major nutrients would be altered on farmed as compared to a paired reference beach. We speculated that ammonium concentration would be greater in sediments of farmed versus reference sites, whereas given their redox sensitivity, iron and manganese would be less abundant. As the cycling of phosphorus is coupled to that of iron, phosphorus would be less as well. We did not measure abiotic factors such as oxygen or nutrient flux rates as in Giles (2006), rather, we looked to the overall differences in geochemical components that indicate the prevailing abiotic conditions for farmed as compared to reference sites.

In the Tier II and Tier III studies, we attempted to determine how geochemical cycles were being altered in the absence of predator netting but with a community composition that represented a farmed versus reference beach. In this way, we hoped to decouple the influence of predator netting on geochemical cycles from the influence of changes in community composition. For example, Norling \& Kautsky (2007) studied the structural and functional effects of Mytilus edulis on diversity of associated species and ecosystem functioning. The result of their study of natural populations plus manipulative studies was that mussel biodeposition accounted for 24 to $31 \%$ of the associated community energy demand, and further concluded that the energy balance of the community was dependent on the function of live mussels with mussel biodeposition and nutrient regeneration supplying limiting resources and thus increasing carrying capacity. This also had been documented for suspended mussels in aquaculture i.e. the local enhancement of epibenthic macrofauna as a result of suspended mussel culture (e.g. D'Amours et al. 2008).

As expected, Tier I studies indicated that surficial sediments of farmed sites contained more organic mat- 

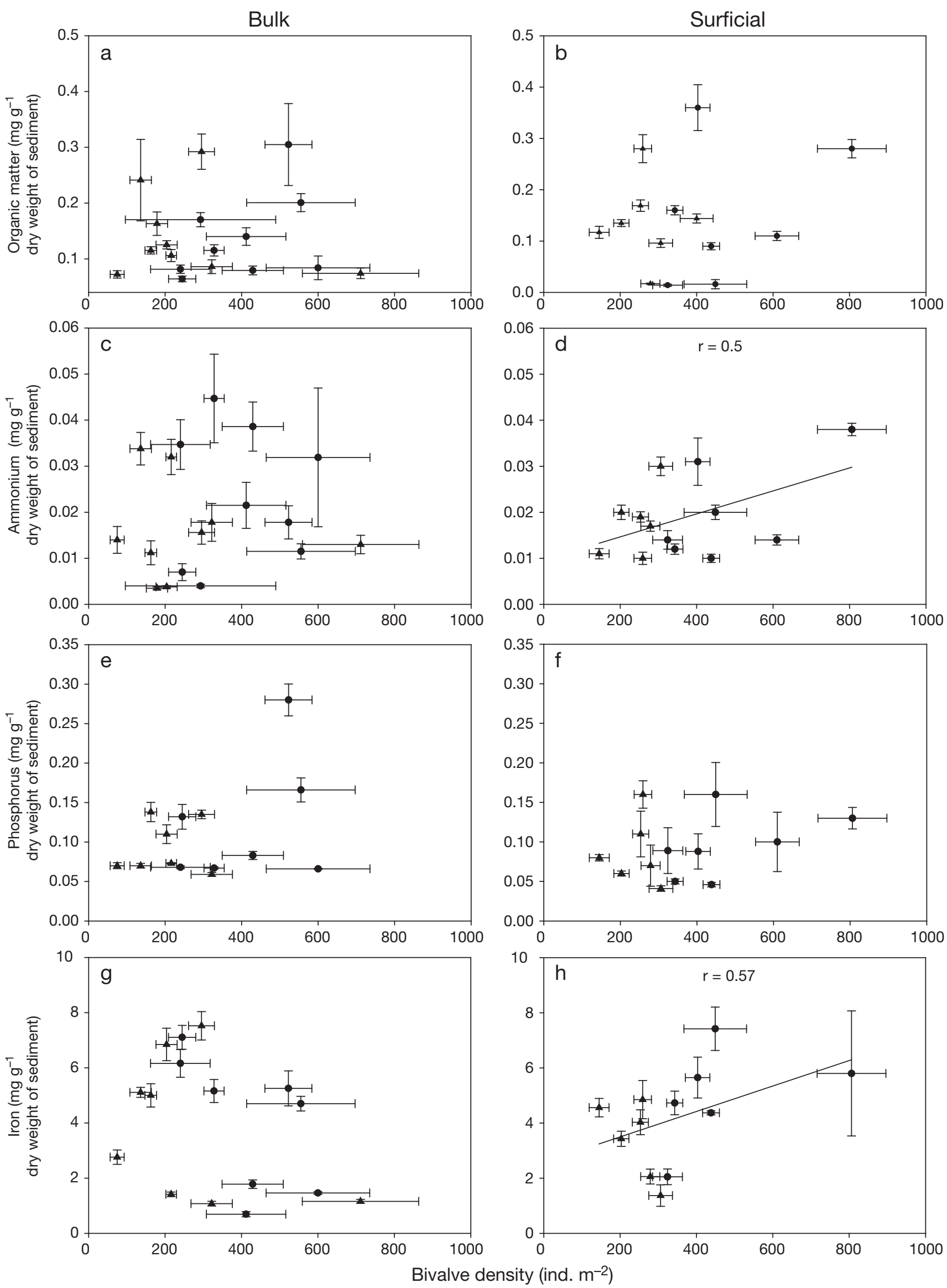
Fig. 4. Bivariate plot of bulk and surficial sediment geochemical attributes with bivalve density. Means \pm 1 SE. Regressions for ammonium and iron are significant at p < 0.05 (manganese and silt not shown). (•) farmed sites, (₫) reference sites

ter, ammonium and silt as compared to reference sites. In marked contrast to our prediction, concentrations of iron and manganese were greater as well. Surficial phosphorus did not differ between farmed and reference sites. For bulk sediments, concentrations of ammonium, phosphorus and again manganese were greater on farmed as compared to reference sites whereas silt, iron and organic matter were the same. Tier II studies suggested that the natural population of epibenthic species, mussels and barnacles were important for contributing to amounts of ammonium, iron and organic matter recovered from surficial sediments but not phosphorus, which was dependent on the presence of bivalves. Finally, Tier III studies indicated that rates of ammonium diffusion were greater in micro-

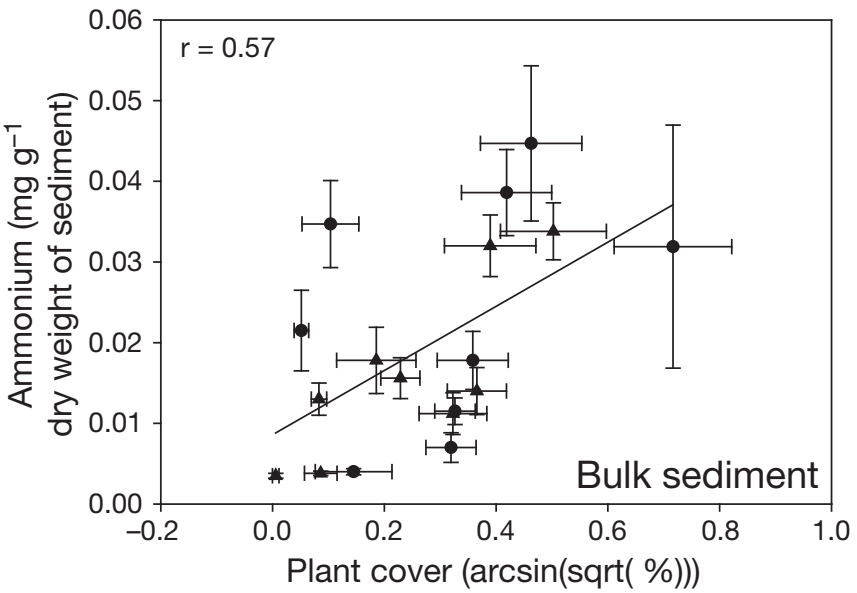

Fig. 5. Bivariate plot of bulk sediment ammonium concentrations with $\%$ plant cover. Correlation is significant at $\mathrm{p}<0.05$.

Means $\pm 1 \mathrm{SE}$

cosms, which had Manila clams, mussels and barnacles present as compared to microcosms with only Manila clams or mussels and barnacles.
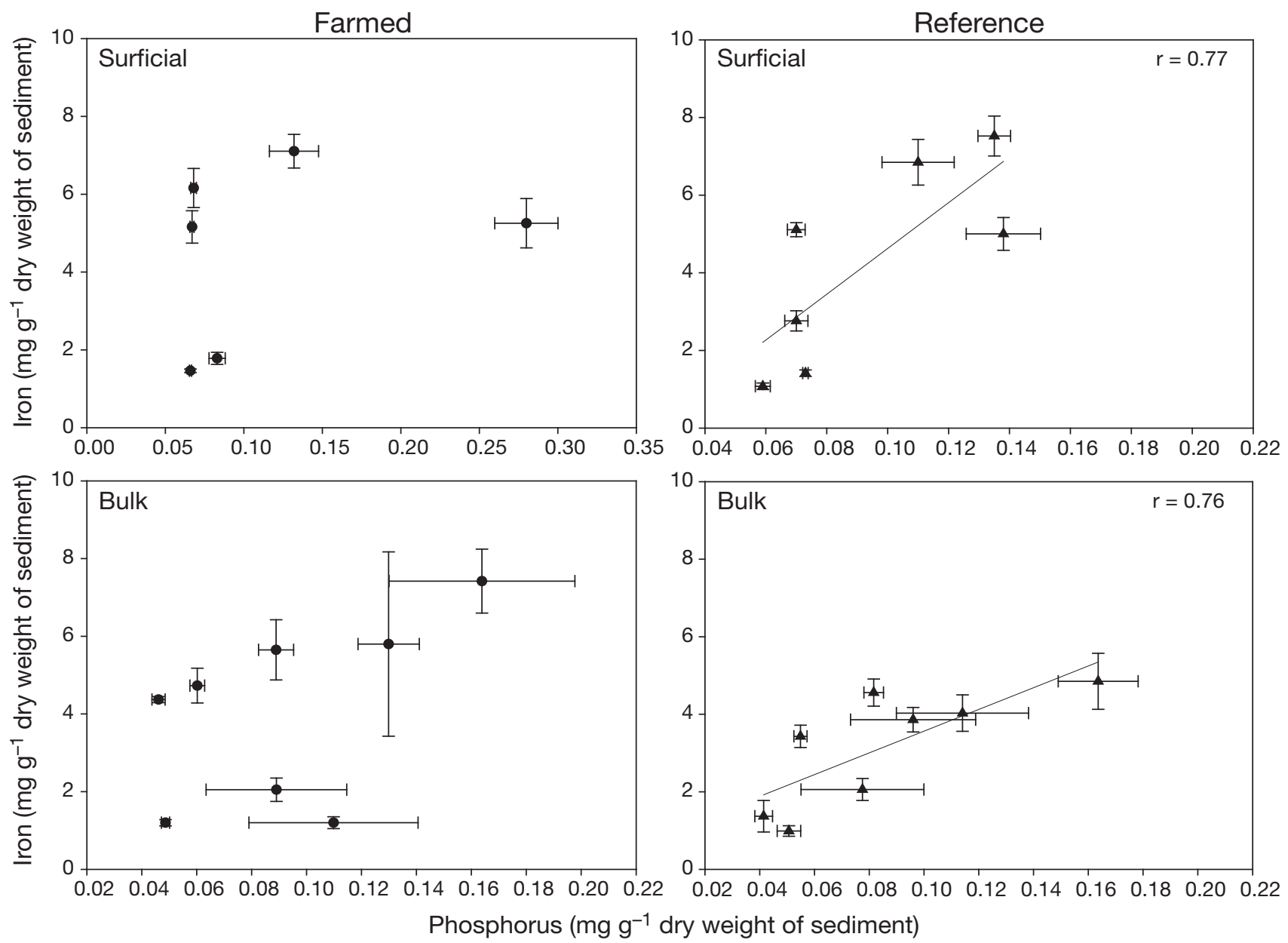

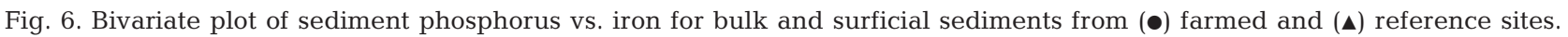
Correlation is significant at $\mathrm{p}<0.05$ 
102

Mar Ecol Prog Ser 404: 91-108, 2010
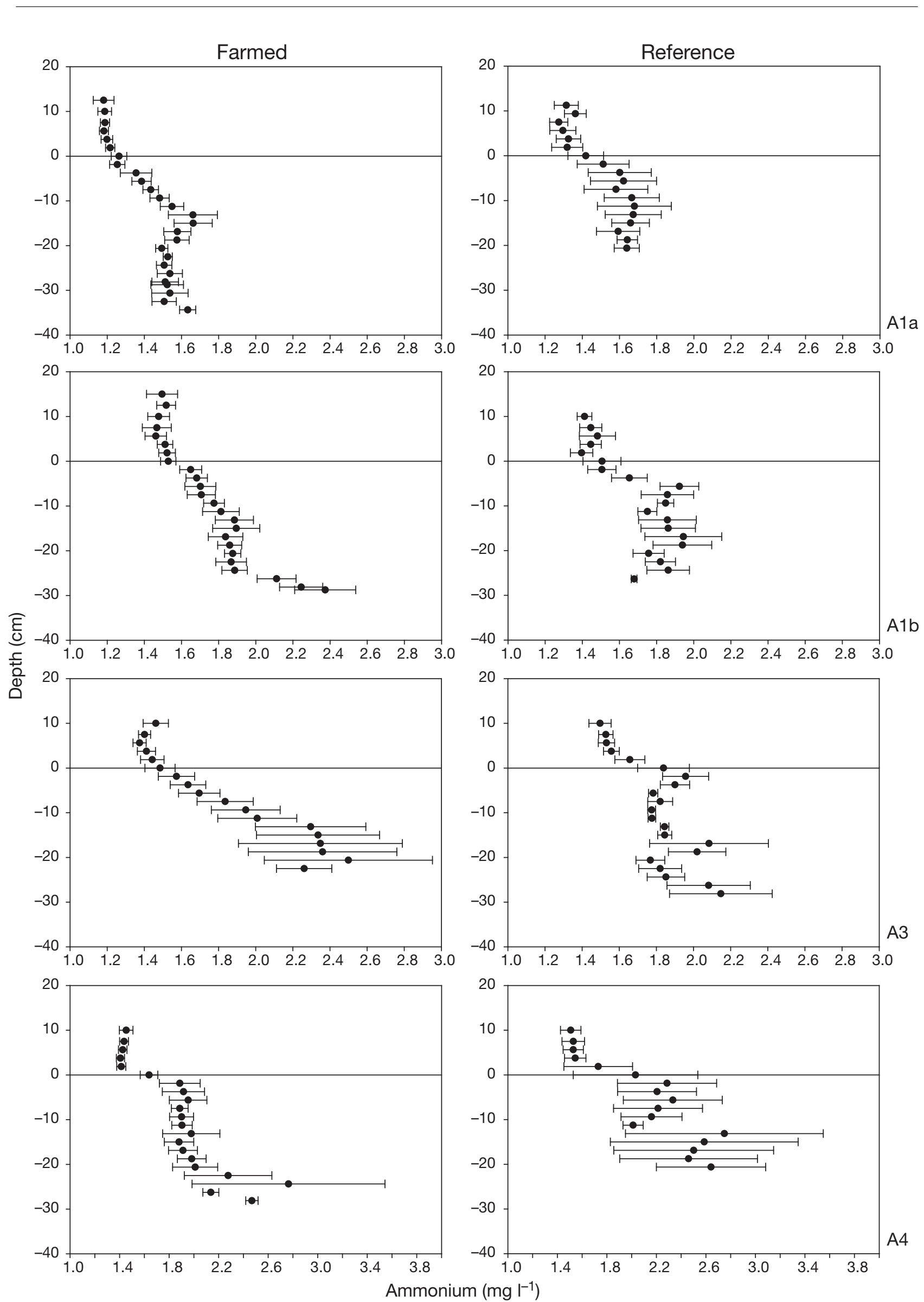
Fig. 7. Ammonium pore water profiles for paired farmed and reference sites A1a, A1b, A3, A4 in Baynes Sound. Mean $\pm 1 \mathrm{SE}, \mathrm{n}=4$ to 6
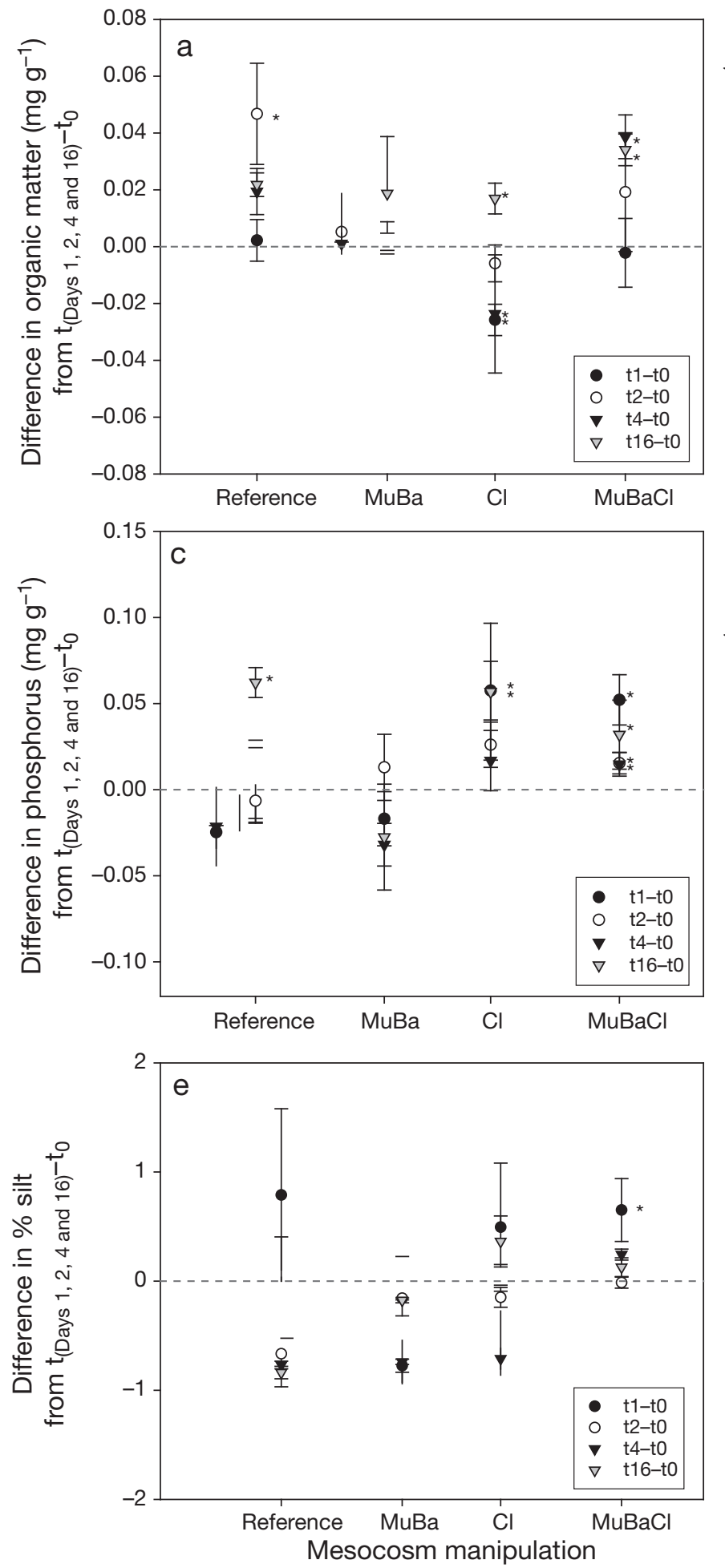

\section{Organic matter and silt}

In agreement with previous studies (e.g. Simenstad et al. 1993, Spencer et al. 1997, Bendell-Young 2006) both organic matter (in surficial sediments) and silt were greater in concentration on farmed versus refer-
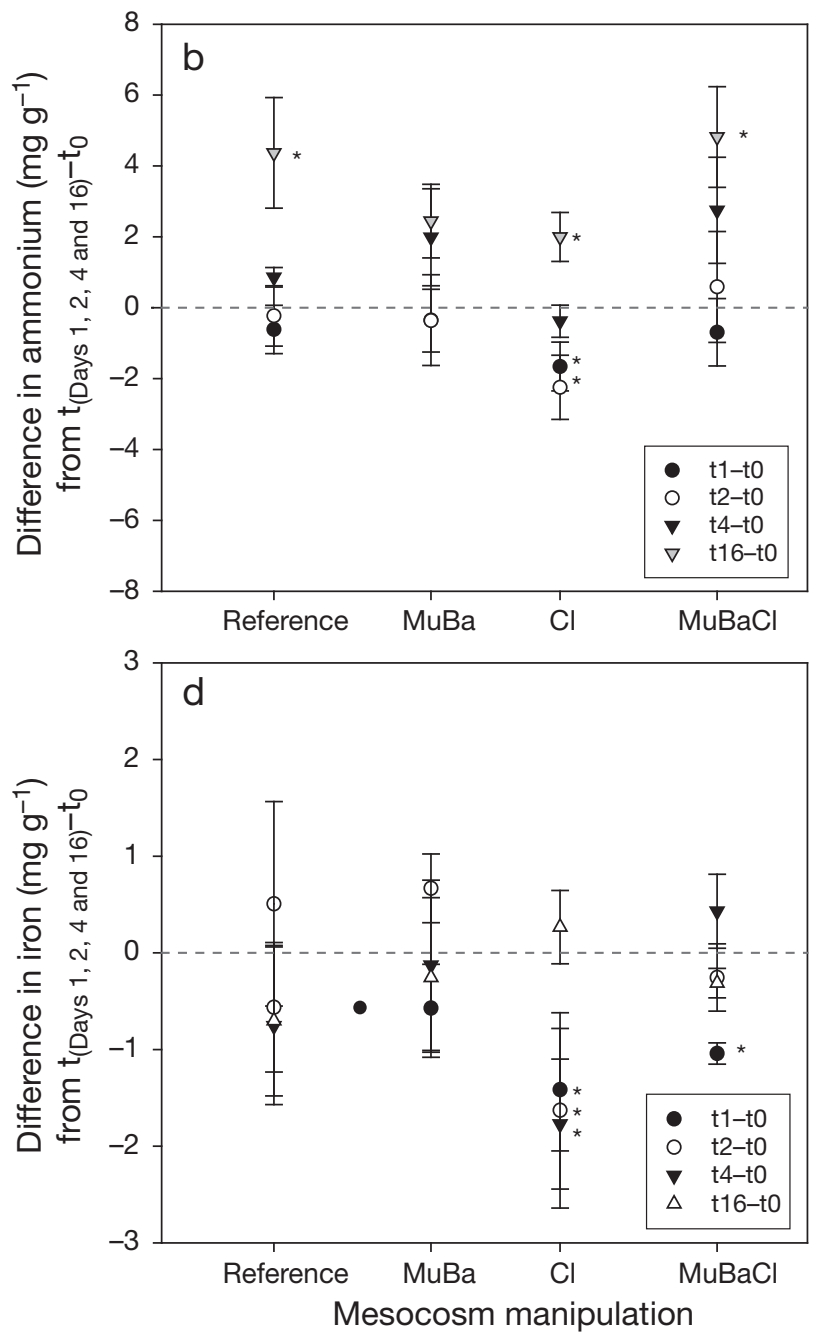

Fig. 8. Mesocosm manipulations. Differences in concentrations of (a) organic matter, (b) ammonium, (c) phosphorus, (d) iron and (e) silt for the 4 community treatments. Reference: no invertebrates added, MuBa: mussels and barnacles, Cl: Manila clams, $\mathrm{MuBaCl}$ : mussels, barnacles and Manila clams. ${ }^{*}$ Significant differences in nutrient concentrations $(\mathrm{p}<0.1)$. Mean $\pm 1 \mathrm{SE}, \mathrm{n}=9$ 

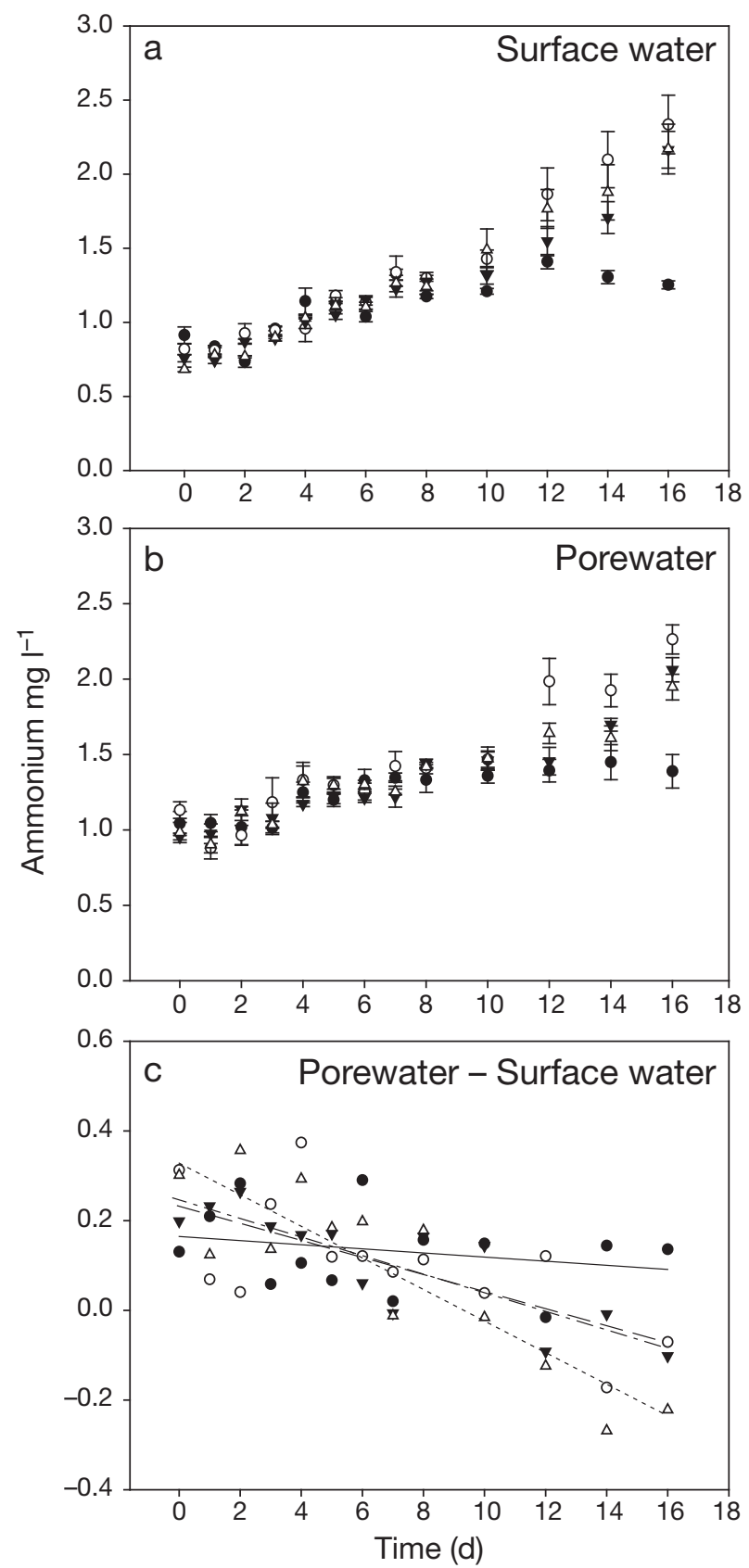

Fig. 9. Concentrations of ammonium in (a) surface waters, (b) pore waters and (c) differences in concentration (ammonium in pore water) - (ammonium in surface water $)=$ (rates of ammonium diffusion) for the 4 community treatments. (•) control, (০) Manila clams only, ( $\mathbf{v})$ mussels and barnacles, $(\Delta)$ Manila clams, mussels and barnacles. Mean $\pm 1 \mathrm{SE}, \mathrm{n}=3$. Except the control, regressions are significant at $\mathrm{p}<0.05$. Regressions: Control $-\mathrm{y}=0.16-0.0045 \mathrm{t} ; \mathrm{r}^{2}=0.06$. Manila clams - - : $\mathrm{y}=0.23-0.019 \mathrm{t} ; \mathrm{r}^{2}=0.46$. Mussels and barnacles - - - - : y $=0.25-0.02 t_{;} r^{2}=0.72$. Manila clams, mussels and barnacles - - -: $\mathrm{y}=0.32-0.035 \mathrm{t} ; \mathrm{r}^{2}=0.78$

ence sites. Tier II studies suggest that bivalves are not directly responsible for these increased amounts: mesocosms with bivalves only tended to accumulate less organic matter as compared to those with either mussels and barnacles or all 3 invertebrate species present. Except for Day 1, accumulations of silt did not differ among the 4 treatments. Rather, in the absence of nets, mussels and barnacles increase amounts of organic matter in surficial sediments. The density of bivalves and the amount of organic matter were weakly correlated, however, this may be due to the nets enhancing sedimentation of organic matter as well as silt as a consequence of reduced surface flow under the nets during submergence rather than to the increased density of bivalves.

An interesting result of the Tier II study was the great amount of silt recovered from all 4 treatments on Day 1 as compared to the remaining 3 sample days. As this occurred in the reference mesocosm as well as the other 3 treatments an artifact due to the introduction of the invertebrates included. This may be an effect of digging in the surrounding area by recreational shellfish collectors, leading to increased silt deposition with the outgoing tide.

\section{Ammonium}

Much work has been devoted to the influence of shellfish aquaculture on the geochemical cycle of nitrogen; however, these studies have focused on raft cultures. The influence of sea bed mariculture and antipredator nets on nitrogen dynamics within the intertidal is not well known (reviewed in Newell 2004). With oxygen present, various inorganic compounds of nitrogen exist, i.e. nitrate, nitrite, ammonium and nitrogen gas. When oxygen is absent, nitrate is dentrificated and ammonium accumulates in sediments, the latter appears to occur on farmed sites. Nitrogen measured as ammonium was greater in farmed bulk and surficial sediments as compared to reference sediments.

Tier II studies suggest that increased amounts of ammonium in farmed sediments may not be due to the presence of bivalves, since those mesocosms with bivalves only had in general less ammonium in sediments as compared to those with all 3 invertebrate species present. A notable exception to the general trends were greater levels of recoverable ammonium from all mesocosms on Day 16. While on previoous sampling days average temperature was $21^{\circ} \mathrm{C}$ over the $4 \mathrm{~d}$ period, the temperature on Day 16 was $27^{\circ} \mathrm{C}$. Sampling took place after exposure at low tide; hence, high ammonium concentration could be due to increased microbial activities at the high temperature. Flux of ammonium from both sandy and muddy sediments in a shallow coastal lagoon have been shown to be sensitive to differences in temperature, with greater fluxes 
noted during summer as compared to cooler seasons (Serpa et al. 2007).

Ammonium was not supplied to intertidal sediments via ground water as indicated by the pore water profiles; however, there was greater sorption of ammonium by surficial sediments of farmed as compared to reference sites. Koop-Jakobsen \& Giblin (2002) determined the influence of tidal flushing on adsorbed ammonium from intertidal salt marsh sediments and noted that the pool of sorbed ammonium could account for a significant amount of ammonium that is released into the overlying water during periods of flood tide with this effect being most pronounced in the upper 0 to $1 \mathrm{~cm}$ of sediment. This tidal flushing could be restricted by anti-predator nets, especially if biofouled, leading to the observed higher Kd for farmed sites as compared to reference sites. Ammonium sorption coefficients have also been shown to be positively correlated to carbon (Hou et al. 2003). These authors concluded that sediment organic matter might be one of the main factors controlling ammonium adsorption. In our study, Kd positively correlated with organic matter, although weakly $(\mathrm{r}=0.4 ; \mathrm{p}<0.05)$, in agreement with the findings of Hou et al. (2003). Further, amounts of ammonium in bulk sediments correlated significant with \% plant cover, $(\mathrm{r}=0.57$; $\mathrm{p}<0.05)$ with farmed sites having more plant cover than have reference sites. Corzo et al. (2009) has recently documented the effects of green macroalgae blooms, the same alga that occurs on our study sites, Ulva spp. on intertidal sediments, specifically with respect to carbon and nitrogen contents. These authors noted that concentrations of inorganic nutrients in the sediments were always higher below the macroalgae mat than in bare sediments, and suggested this was likely due to a direct input of inorganic nitrogen (and phosphate) associated with the macroalgae debris. Another mechanism leading to increased amounts of ammonium in sediments of farmed versus reference sites could be related to fewer epibenthic species on farmed sites. Tier III studies indicate that the flux of ammonium from the sediment to the overlying water column would be less in a benthic community comprised just of bivalves as compared to one with the presence of epibenthic species.

\section{Iron and phosphorus}

The strong interaction of iron and phosphorus in estuarine and marine systems is well documented (e.g. Prastka \& Jickells 1995, Rozan et al. 2002, Jordan et al. 2008). Rozan et al. (2002) determined the seasonal relationship between iron, sulphur and phosphorus in a shallow intercoastal bay and concluded that the iron redox cycle was controlling the release of phosphorus into the overlying water column and that iron oxides act as a barrier to diffusive phosphorus flux. Jordan et al. (2008) studied the changes in phosphorus biogeochemistry along an estuarine salinity gradient and noted that 50 to $90 \%$ of the particulate phosphorus was bound to iron oxides and that suspended sediments from the watershed and deposited sediments in the tidal freshwater had the highest concentrations of ironphosphate complexes. Jensen et al. (1995) studied the cycling of phosphorus in coastal marine sediments at $16 \mathrm{~m}$ depth. These authors concluded that adsorption onto oxides of iron (FeOOH) was probably the most important factor controlling sediment phosphorus release. Hyacinthe \& Van Cappellen (2004) found a discrete iron-phosphorus phase in intertidal freshwater sediments from the eutrophic Scheldt estuary accounting for $<70 \%$ of total phosphorus in the sediments. Finally, Slomp et al. (1996) describe phosphorus binding by poorly crystalline iron oxides in North Sea sediments that can act both as a temporary or permanent sink for phosphorus in continental margin sediments.

We postulated that, due to anaerobic conditions, both phosphorus and iron would be lowly concentrated in farmsite sediments. Rather, both elements were either the same or higher concentrated on farmed versus reference sites. Although absolute concentrations did not follow predictions, the co-occurrence of iron and phosphorus did differ between farmed and reference sites. For reference sites and in agreement with the reported behavior of iron and phosphorus within coastal sediments (e.g. above cited references), there was a strong positive correlation between the 2 elements for both surficial and bulk sediments. In contrast, this correlation did not occur for sediments from farmed sites. This suggests that on the farmed sites the geochemical association between the 2 nutrients becomes uncoupled. This would occur if conditions tended towards low oxygen. However amounts of phosphorus and iron are greater on farmed versus reference sites: phosphorus in bulk sediments, iron in surficial sediments.

High phosphorus contents in bulk sediments suggest that this element is accumulating over time in sediments of farmed sites. Tier II studies indicate that bivalves are contributing to the amount of phosphorus in the sediments as mesocosms with bivalves only accumulated phosphorus as compared to the reference and the mussel and barnacle mesocosms. This difference occurred at bivalve densities representative of reference beaches (i.e. 200 clams $\mathrm{m}^{-2}$ ). Farmed beaches can have up to 400-600 Manila clams $\mathrm{m}^{-2}$. Thus, greater amounts of phosphorus on farmed sites could be a result of more biodeposits from the higher density of clams rather than phosphorus associated 
with iron oxides. Biodeposits have been shown to be key drivers in the cycling of nitrogen, especially in the case of suspended mussel aquaculture. However, their role in the cycling of phosphorus is as yet unclear (e.g. Newell 2004 and references therein). One possibility is that on farmed sites, phosphorus is associated with biodeposits, whereas on reference sites, it remains coupled with iron oxides. If so, then phosphorus on farmed sites may occur in possibly less biologically available forms within the fecal deposits, which in turn accumulates within the sediments as compared to reference sites. Haven \& Morales-Alamo (1966) studied the chemical composition of biodeposits from of the oyster Crassostrea virginica and determined that the deposits contained 77 to $91 \%$ inorganic matter, 4 to $12 \%$ organic carbon and $1 \mathrm{~g} \mathrm{~kg}^{-1}$ phosphorus. These authors also noted that biodeposits of other filter feeders such as barnacles, tunicates or lamellibranches were similar. Further study on the speciation of phosphorus on farmed versus reference sites is warranted.

\section{Iron and manganese}

That iron and manganese concentrations are greater in sediments of farmed versus reference precludes the role of low oxygen in determining amounts of these micronutrients recovered from the sediments. If redox conditions were controlling the elemental chemistry, it would be expected that both elements be less abundant, as both would be transformed from their less soluble oxide form into their reduced easily soluble state (e.g. Thomas \& Bendell-Young 1999). An alternate possibility could be related to the practice of seeding on the farmed sites. Manila clam seed is grown in a medium enriched in essential nutrients such as iron and manganese and may explain the differences seen here. For example, Jones et al. (1993) include a recipe for a nutrient solution designed to optimise algae growth. Included in the nutrient solution are ferric sequestrene, ferric ammonium citrate and manganese chloride. When farmers are applying seed, this could serve as a source of both iron and manganese to farmed sites (and also ammonium). Hence, recovered iron and manganese would not be completely associated with intertidal geochemical cycles, but rather related to shellfish farming practices, i.e. the application of seed. If so, then on farmed sites iron would not be associated with phosphorus as oxides, but rather in another complex form. Similarly, manganese would not be as oxides, but associated with chlorides. Again, as noted for phosphorus, further study that addresses the speciation of these elements on the foreshore in relation to shellfish farming activities is required.
The important functional trait with respect to farming that is being altered is the role of epibenthic species acting as ecosystem engineers in the movement of materials from the overlying water column to the sediment, i.e. benthic-pelagic coupling. Manila clams feed mostly on resuspended sediments, close to the sediment-water interface (Watanabe et al. 2009) rather than actually filtering particles from the overlying water column as do mussels or barnacles. The consequence which this shift in community structure will have on the movement of nutrients such as iron, phosphorus, organic matter and ammonium to the sediment-water interface is as yet unknown. All geochemical attributes were greater in sediments of farmed as compared to reference beaches. Ammonium sorption coefficients were also greater in surface sediments of farmed versus reference beaches. Tier III studies indicated that the flux of ammonium to surface waters was less in microcosms with only bivalves (0.019 $\left.\mathrm{mg} \mathrm{l}^{-1} \mathrm{~d}^{-1}\right)$ as compared to those with mussels, barnacles and bivalves (0.03 $\mathrm{mg} \mathrm{l}^{-1} \mathrm{~d}^{-1}$ ), which would also contribute to greater amounts of ammonium in sediments of farmed versus reference sites. Bivariate plots of the geochemical attributes with bivalve density and \% plant coverage and the Tier II mesocosm studies suggest that greater recovery of ammonium and phosphorus may be in part related to the increased bivalve density and \% plant coverage on farmed versus reference sites. In contrast, greater amounts of organic matter and silt are likely a result of the presence of nets. Shellfish farming practices uncouple the geochemical cycles of iron and phosphorus. Greater amounts of iron and manganese recovered from farmed sediments maybe related to nutrients associated with the application of seed rather than to nets or the greater number of bivalves and \% plant coverage on farmed sites.

Shellfish farming appears to create conditions that favour accumulation of organic matter, phosphorus, silt and ammonium. Practices that ensure well aerated sediments and support a diverse intertidal community would be advised. Important nutrient geochemical cycles should not be affected to maintain the quality of habitat and primary productivity. Further studies will focus on the speciation of phosphorus and iron as well as on $\mathrm{N}_{2}$ flux from sediments as a function of community composition. If the intertidal, through aggressive farming techniques and/or invasive species such as the varnish clam, is changed towards accumulations of organic matter, phosphorus, silt and ammonium and is enhanced by denitrification $\mathrm{N}_{2}$ flux, the amounts of essential nutrients for primary productivity could be influenced. This will have important implications for both intertidal and oceanic primary and hence secondary productivity. 
Acknowledgements. The authors thank the shellfish farmers for access to their farms, without which this study would not have been possible. The contribution of Dr. D. Varela to the microcosm studies is also gratefully acknowledged. Field assistance of M. Kirk, I. McKeachie, K. Hendersen, D. Leung, N. Martens, V. Sadler, R. Davidson, B. Bartzen, R. Dickson and T. Lewis is gratefully appreciated. The authors also thank N. Cook for the use of mesocosms. Funding for this study was through a National Science and Engineering Research Council (NSERC) Strategic Operating Grant (STPGP24607901) to LB.

\section{LITERATURE CITED}

Bartoli M, Nissoli D, Viaroli P, Turolla E, Castaldelli G, Fano A, Rossi R (2001) Impact of Tapes philippinarum farming on nutrient dynamics and benthic respiration in the Sacca di Goro. Hydrobiologia 455:203-212

Beadman HA, Kaiser MJ, Galanidi M, Shucksmith R, Willows RI (2004) Changes in species richness with stocking density of marine bivalves. J Appl Ecol 41:464-475

Bendell-Young L (2006) Contrasting the community structure and select geochemical characteristics of three intertidal regions in relation to shellfish farming. Environ Conserv 33:21-27

Burgin AJ, Hamilton SK (2007) Have we overemphasized the role of denitrification in aquatic ecosystems? A review of nitrate removal pathways. Front Ecol Environ 5:89-96

Corzo A, van Bergeijk SA, Garcia-Robledo E (2009) Effects of green macroalgal blooms on intertidal sediments: net metabolism and carbon and nitrogen contents. Mar Ecol Prog Ser 380:81-93

D'Amours O, Archambault P, McKindsey CW, Johnson LE (2008) Local enhancement of epibenthic macrofauna by aquaculture activities. Mar Ecol Prog Ser 371:73-84

DFO (2006) Assessing habitat risks associated with bivalve aquaculture in the marine environment. Department of Fisheries and Oceans Can. Sci. Advis. Sec. Sci. Advis. Rep. 2006/005

Dudas SE (2005) Invasion dynamics of a non-indigenous bivalve, Nuttallia obscurata, (Reeve 1857), in the Northeast Pacific. PhD thesis, University of Victoria

> Dudas SE, Dower JF (2006) Reproductive ecology and dispersal potential of varnish clam Nuttallia obscurata, a recent invader in the Northeast Pacific Ocean. Mar Ecol Prog Ser 320:195-205

Enoksson V (1993) Nutrient recycling by coastal sediments: effects of added algal material. Mar Ecol Prog Ser 92: 245-254

Fulweiler RW, Nixon SW, Buckey BA, Grander SL (2007) Reversal of the net dinitrogen gas flux in coastal marine sediments. Nature 448:180-182

Giles H (2006) Dispersal and remineralisation of biodeposits: ecosystem impacts of mussel aquaculture. PhD thesis, University of Waikato, Hamilton

Greenberg AE, Clesceri LS, Eaton AD (1992) Standard methods for the examination of water and wastewater. 18th edn. American Public Health Association, Washington DC, WA

Gunnars A, Blomqvist S (1997) Phosphate exchange across the sediment-water interface when shifting from anoxic to oxic conditions: an experimental comparison of freshwater and brackish-marine systems. Biogeochemistry 37 : 203-226

Haven DS, Morales-Alamo R (1966) Aspects of biodeposition by oysters and other invertebrate filter feeders. Limnol Oceanogr 115:487-498
Hou LI, Jiang HY, Ou DN, Liu QM, Shang BL (2003) Ammonium adsorption by tidal flat surface sediments from the Yangtze Estuary. Environ Geol 45:72-78

Hyacinthe C, Van Cappellen P (2004) An authigenic iron phosphate phase in estuarine sediments: composition, formation and chemical reactivity. Mar Chem 91:227-251

Jamieson GS, Chew L, Gillespie G, Robinson A, and 6 others (2001) Phase 0 review of the environmental impacts of intertidal shellfish aquaculture in Baynes Sound. Canadian Science Advisory Secretariat Research Document 2001/125, ISSN 1480-4883, available at www.dfompo.gc.ca/csas/

Jensen HS, Mortensen PB, Andersen FO, Rasmussen E, Jensen A (1995) Phosphorus cycling in a coastal marine sediment, Aarhus Bay, Denmark. Limnol Oceanogr 40: 908-917

Jickells TD, Rae JE (1997) Biogeochemistry of intertidal sediments. Cambridge Environmental Chemistry Series, Cambridge University Press, Cambridge

Jones GG, Sanford CL, Jones BL (1993) Manila clams: hatchery and nursery methods. Innovative Aquaculture Products Ltd., Skerry Bay Lasqueti Island

Jordan TE, Cornwell JC, Boynton WR, Anderson JT (2008) Changes in phosphorus biogeochemistry along an estuarine salinity gradient: the iron conveyer belt. Limnol Oceanogr 53:172-184

Koop-Jakobsen K, Giblin A (2002) Tidal flushing of ammonium from intertidal salt marsh sediments: the relative importance of adsorbed ammonium. Biol Bull 203:258-259

Lamb A, Hanby BP (2005) Marine life of the Pacific Northwest. Harbour Publishing, Maderia Park

MoE (2006) Ecosystems at risk: estuaries in British Columbia. BC Conservation Data Center, Ministry of the Environment, Victoria, available at: www.env.gov.bc.ca/cdc/

Newell RIE (2004) Ecosystem influences of natural and cultivated populations of suspension-feeding bivalve molluscs: a review. J Shellfish Res 23:51-61

Nollet LML (ed) (2000) Handbook of water analysis. Marcel Dekker, New York

> Norling P, Kautsky N (2007) Structural and functional effects of Mytilus edulis on diversity of associated species and ecosystem functioning. Mar Ecol Prog Ser 351:163-175

Osborne J, Overbay A (2004) The power of outliers (and why researchers should always check for them). Practical Assessment. Res Eval 9(6). Available at: http://pareonline. net/getvn. asp? $v=9 \& n=6$

Page AL, Miler RH, Keeny DR (1982) Methods of soil analysis. Part 2: Chemical and microbiological properties, 2nd edn. American Society of Agronomy, Soil Science Society of America, Madison, WI

Powers MJ, Peterson CH, Summerson HC, Powers SP (2007) Macroalgal growth on bivalve aquaculture netting enhances nursery habitat for mobile invertebrates and juvenile fishes. Mar Ecol Prog Ser 339:109-122

Prastka KE, Jickells TD (1995) Sediment geochemistry of phosphorus at two intertidal sites on the Great Ouse estuary, S. E. England. Aqua Ecol 29:245-255

Rozan TF, Taillefert M, Trouwborst RE, Glazer BT, Shufen M (2002) Iron-sulfur-phosphorus cycling in the sediments of a shallow coastal bay: implications for sediment nutrient release and benthic macroalgal blooms. Limnol Oceanogr 47:1346-1354

Serpa D, Falcao M, Duarte P, Cancela da Fonseca L, Vale C (2007) Evaluation of ammonium and phosphate release from intertidal and subtidal sediments of a shallow coastal lagoon (Ria Formosa-Portugal): a modelling approach. Biogeochem 82:291-304 
Simenstad CA, Weitkamp LA, Cordell JR (1993) Effects of substrate modification on littoral flat epibenthos: assemblage structure changes associated with predator exclusion nets. FRI-UW-9310, Fisheries Research Institute, University of Washington, Seattle, WA

Slomp CP, Van der Gaast SJ, Raaphorst WV (1996) Phosphorus binding by poorly crystalline iron oxides in North Sea sediments. Mar Chem 52:55-73

Smaal A, Stralen van M, Schuling E (2001) The interaction between shellfish culture and ecosystem processes. Can J Fish Aquat Sci 58:991-1002

Solan M, Cardinale BJ, Downing A, Engelhardt KAM, Ruesink JL, Srivastava DS (2004) Extinction and ecosystem function in the marine benthos. Science 306:1177-1179

Sorokin I, Giovanard O, Pranovi F, Sorokin P (1999) Need for restricting bivalve culture in the southern basin of the Lagoon of Venice. Hydrobiologia 400:141-149

Spencer BE, Kaiser MJ, Edwards DB (1997) Ecological effects of intertidal Manila clam cultivation: observations at the end of the cultivation phase. J Appl Ecol 34:444-452

Testa JM, Charette MA, Sholkovitz ER, Allen MC, Rago A (2002) Dissolved iron cycling in the subterranean estuary

Editorial responsibility: Matthias Seaman,

Oldendorf/Luhe, Germany of a coastal bay: Waquoit Bay, Massachusetts. Biol Bull 203:255-256

> Thomas C, Bendell-Young L (1999) The significance of diagenesis versus riverine input in contributing to the sediment geochemical matrix of iron and manganese in an intertidal region. Estuar Coast Shelf Sci 48:635-647

Twichell S, Sheldon S, Deegan L, Garritt R (2002) Nutrient and freshwater inputs from sewage effluent discharge alter benthic algal and infaunal communities in a tidal salt marsh creek. Biol Bull 203:256-258

- Watanabe S, Katayama S, Kodama M, Cho N, Nakata K, Fukuda M (2009) Small-scale variation in feeding environments for the Manila clam Rudiptapes philippinarm in a tidal flat in Tokyo Bay. Fish Sci 75:937-945

Whiteley JA (2005) Macroinvertebrate community responses to clam aquaculture practices in British Columbia, Canada. MSc thesis, Simon Fraser University, Burnaby

Whiteley JA, Bendell-Young L (2007) Ecological implications of intertidal mari-culture: observed differences in bivalve community structure between farm and reference sites. J Appl Ecol 44:495-505

Submitted: May 13, 2009; Accepted: January 11, 2010 Proofs received from author(s): March 16, 2010 